dyne. I use vis (pl. vires) to express the absolute unit of force in the F.P.S. system of units, with the multiples decemvires, centivires, millivires. Thus nine centivires is very closely equal to the weight of twenty. eight pounds in this country.

I should add that the distinction between "weight" and "mass," generally recognised, but not uniformly insisted on in practice, is clearly pointed out in Prof. Everett's useful tables.

University Hall, March I8 J. J. WALKER

\section{The Dry River-beds of the Riviera}

THOSE who have visited the Riviera of Piedmont will remember as one of its most remarkable features the broad stony river-beds, sometimes with a meagre rill trickling down a narrow channel in the middle, sometimes entirely dry, but never with any body of water sufficient to account for the immense bed; the Paglione at Nice, with its bed spanned by a bridge of three broad arches, and with a stream never more than four or five feet wide and a few inches deep, is a specimen of what I mean. Can any of your scientific readers tell me what and when was the change of climate which caused what must once have been large rivers to shrink into mere rivulets? To all appearance it must have been within historical times, as the river-beds are dis. tinct and still bare, without any encroachment of vegetation. Probably the simplest way of accounting for the phenomenon would be, by showing that there has been a great diminution in the snow lying on the Alpes Maritimes, which are drained by these rivers. It is remarkable, too, that in many of the narrow valleys running up into the hills, now quite dry, there are evident traces of torrents and waterfalls apparently in recent times.

Nice, March 7

\section{The Ocelli in Insects}

A T vol. xiii, p. I68, H. Muiller calls the attention of eistomologists to a subject which has interested other entomologists before-the function of the ocelli in insects. With due deference to a suggestion made by such an authority, it seems to me that the size of the ocelli in hymenopterous insects is not dependent on their nocturnal habits. Why in hymenoptera more than in other orders? Indeed, it may be doubred whether in some insects the ocelli are organs of vision at all, or at least whether they are of any practical use as such in the imago. Their number, as well as size, differs in different species of the same, order, seemingly without regard to their habits, whether diurnal or nocturnal, and in many moths they are so completely concealed by the scales that it is necessary to divide the head to ascertain whether they are present or absent, so that it is difficult to understand how they can be of any service as organs of vision. May they not in the imago, in such cases, be merely functional remnants of larval organisations.

Colorado, Feb, I5

\section{The Recent Storm}

YouR meteorological readers will probably guess that I have made an error of an inch inadvertently in the barometer readings of Sunday week. Also the last line should contain "nine hours" in place of seven.

Staplehurst, Kent, March 2 I

\section{OUR ASTRONOMICAL COLUMN}

STRUVE'S Companion OF Procyon.-Mr. Otto Struve, in his remarks at the Royal Astronomical Society, in May, 1874 , upon the later Pulkowa observations of the faint companion to Procyon, which he discovered on March 19,1873 , and which has been supposed to account for the anomalous motion of the latter, established by the researches of Prof. Auwers, referred to the circumstance of the small star not having been up to that time perceived with the 26 -inch refractor of the Washington Observatory. Admiral Davis, the present superintendent of this establishment, has communicated to the Astronomische Nachrichten, the particulars of observations principally instituted for the purpose of confirming the existence of Struve's companion. The observations were commenced in November 1873 , and have been continued to the beginning of the present year. On no single occasion have Professors Newcomb and Holden, the usual observers, or any one who has examined the star with the 26 -inch refractor, been able to detect a companion in the position assigned by the Pulkowa measures. Close faint stars have, however, been remarked in other positionangles, about three of which it is stated no doubt is entertained :--

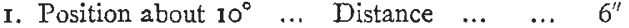

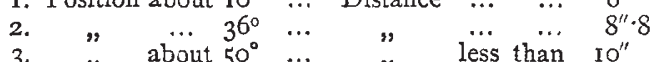

And it is said to be quite possible there may be one or two more. No. 2 is the most readily visible.

Mr. O. Struve's measures gave the following mean results :-

I873, March 28 ... Position $90^{\circ} \cdot 24$... Distance $12^{\prime \prime} \cdot 49$ 1874, April 10 ... $" 99^{\circ} \cdot 60^{\prime}$, , Distance $11^{\prime \prime} \cdot 69$

How then is the contradictory character of the Pulkoxa and Washington observations to be accounted for? It can hardly be, as suggested by Mr. Struve, that "the surpassing brilliancy of the principal star may have hindered the recognition of the small companion in its neighbourhood," since notwithstanding it do ss not appear that a smaller aperture than 22 inches was employed during the Washington observations, three closer companions were considered to be certainly in existence. There remains the supposition of variability of light of the Pulkowa companion, if difference of atmospheric cir. cumstances be ignored as inadequate to explain the want of success of other observers in detecting it.

Nothing more is heard of the Smythian orange tinged eighth magnitude distant from Procyon in $1833,145^{\prime \prime}$ on an angle of $85^{\circ}$. As is well known, the only observation confirmatory of the existence of this star is that by $\mathrm{Mr}$. Isaac Fletcher, M.P., early in March, 1850, which gave for the position $84^{\circ} 19^{\prime}$; most unfortunately the distance was not measured, because there is a star of similar brightness on very nearly the same angle but at a distance of about 330" measured by Capt. Jacob, Mr. Powell, and the late Lord Wrottesley. Anyone, however, who reads Mr. Fletcher's letter to Admiral Smyth, printed in "Sidereal Chromatics," p. 69, will see that there is little doubt the object observed in 1850 was the same that was measured, or rather estimated, as to position in I833, the difference of distance not admitting of a mistake on the part of an experienced and careful astrometer. The more dist int star was judged to be blue by Mr. Powell ; the orange-tinge recorded in "the Cycle" is a characteristic of a large number of the known variable stars.

The Total SOlar EClipse of 1883, May 6.-In this eclipse, in which the duration of totality where the sun is near the meridian will exceed five minutes, the course of the central line appears to be a most unfavourable one for observation, being almost entirely a sea-track. The elements are very approximately as follows:-

Conjunction in R.A., May 6, at 93. 44m. 42s. G.M.T.

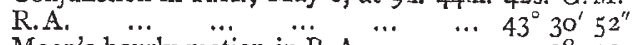

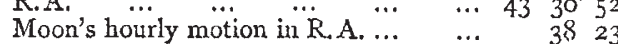

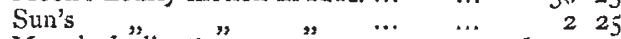

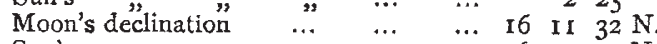

$\begin{array}{llllllll}\text { Sun's } \quad, & \ldots & \ldots & \ldots & 16 & 37 & 53 & \mathrm{~N} \text {. }\end{array}$

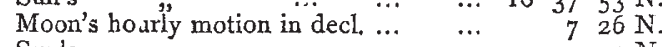

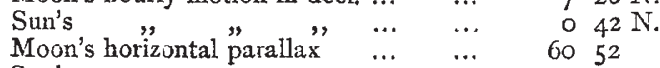

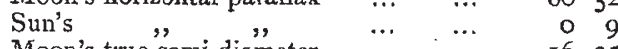

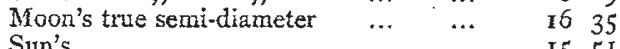

$\begin{array}{llllll}\text { Sun's } \quad ", & \ldots & \ldots & 15 & 35 \\ & \end{array}$

Hence the central and total eclipse begins upon the earth in longitude $156^{\circ} \mathrm{I}^{\prime} \mathrm{E}$. of Greenwich, and latitude $34^{\circ} 43^{\prime} \mathrm{S}$., and ends in longitude $86^{\circ} 44^{\prime} \mathrm{W}$., and latitude $13^{\circ} 4 \mathrm{I}^{\prime} \mathrm{S}$.; the eclipse is central with the sun on the meridian in $147^{\circ} 4^{\prime} \mathrm{W}$, and $9^{\circ} \mathbf{1} \mathbf{I}^{\prime} \mathrm{S}$. The following are also points upon the central line :- 


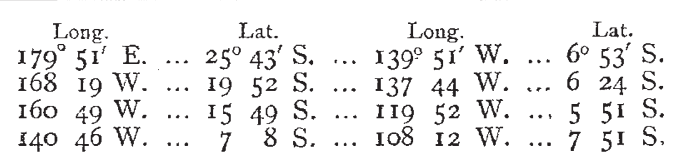

By a direct calculation for a point $I 40^{\circ} 46^{\prime} \mathrm{W} .7^{\circ} 8^{\prime} \mathrm{S}$. in the longitude of the Marquesas, totality is found to commence at oh. $39 \mathrm{~m}$. 30 s. local mean time, duration $5 \mathrm{~m}$. I $5 \mathrm{~s}$, the sun at an altitude of $64^{\circ}$.

The Minor PLANETS.--The four older minor planets, Ceres, Pallas, Juno, and Vesta, are now in pretty favourable positions for observation, and Vesta, which will be in opposition on the 28 th inst., is very little below an average sixth magnitude in brightness, and may probably be detected without the telescope by those who are gifted with strong sight and are acquainted with the planet's position with respect to stars in the vicinity. On the 28 ch it will be a very little to the left of the line joining $\delta$ and $\epsilon$ Virginis, and nearly equi-distant from these stars, which are of the third magnitude.

Niobe, like Euphrosyne, is occasionally situate at a considerable declination. At the beginning of November next she nearly attains $53^{\circ} \mathrm{N}$. in the constellation Camelopardus. An observer who may chance to meet with a small star which he has not before seen at a great distance from the equator, must not too hastily conclude that it belongs to the list of variables.

No. I60 was discovered by Prof. Feters at Clinton, U.S., on the nrorning of Feb. $2 \mathrm{I}$; it has been observed at Marseilles by M. Borrelly.

\section{ON THE ACTION OF LIGHT ON SELENIUM}

$\mathrm{N}$ the $\mathrm{I} 8 \mathrm{th}$ of last month Dr. C. William Siemens gave a lecture to the members of the Royal Institution on the above subject.

Commencing with a general reference to light as a natural force, he showed how little the potential action of light made itself evident to our senses, as with the dis appearance of the light its effects seemed entirely to vanish; he then showed a temporary effect of light by its action on phosphorescent salts, which continue to glow for a long time after the source of light is removed, and drew attention to the permanent effect produced by the decomposition of the salts of silver in photography. He next referred to the radiometer, Mr. Crookes' little machine for illustrating light effects, which he brought forward for the purpose of showing the motive power of light, and closed his introduction by a reference to some experiments which he had made on a fungus that lives in the dark, and which, on analysis, gave no evidence of containing carbon, thus helping to favour the hypothesis that it is not heat, but the ray of light which brecks up carbonic acid in the leaves of plants in order to separate the carbort.

Selenium was discovered in I 8 I 7 by Berzelius, as a bye product from the distillation of iron pyrites. It is fusible, combustible, and similar to sulphur, phosphorus, and tellurium. If melted (at $217^{\circ} \mathrm{C}$.) and cooled rapidly, it presents a brown amorphous mass of conchoidal fracture, presents a brown amonductor of electricity; if heated only to and is a non-conductor some time at this temperature, it becomes crystalline, and is a slight conductor of electricity, the conductivity increasing with battery power, tricity, the coccording to the direction of the current, as lately observed by Prof. Adams.

It was on the 12 th of February, 1873 , that the Society of Telegraph Engineers received a communication from Mr. Willoughby Smith, one of its members, of an observation made first by Mr. May, a telegraph clerk at Valentia, viz. that a stick of crystalline selenium offered considerably less resistance to a battery current when exposed to the light than when kept in the dark; this was corroborated by the Earl of Rosse, who clearly proved the action to be due solely to light, and who also showed the effects of the light of different portions of the spectrum, and afterwards by Lieut. Sale, and conjointly by Messrs. H. N. Draper, F.C.S., and R. J. Moss, F.C.S.

About twelve months ago the matter was again taken up by two independent observers, Prof. Adams in this country, and Dr. Werner Siemens in Germany, and it was to the results obtained by the latter, and which have been communicated to the Academy of Sciences of Berlin, that the lecturer's remarks were chiefly confined.

The sensitive selenium plates made by Dr. Werner Siemens, with which experiments were made, are formed of two spirals of platinum wire, laid upon a plate of mica, in such a manner that the two wires run parallel without touching; upon the plate a drop of molten selenium is allowed to fall, and before solidifying, another plate of mica is pressed down; the two protruding ends of wire serve to insert the selenium element in a galvanic circuit. Amorphus selenium when thus tested produces no deflection of the galvanometer, either in light or darkness. If, however, a selenium disc which has been kept for some time at $100^{\circ} \mathrm{C}$. and then cooled is inserted, a slight deflection of the galvanometer takes place when it is under the influence of light, but none in dirkness. If now a selenium disc which has been kept for several hours at a temperature of $210^{\circ} \mathrm{C}$., a point below that of the fusion of selenium, and which has been gradually cooled, is substituted for the other, a considerable deflection under the influence of light will be observed, whilst a hardly perceptible deflection takes place in the dark.

It was also explained, as the result of an experiment, that amorphous selenium did not conduct up to $80^{\circ} \mathrm{C}$.; from this temperature to $210^{\circ} \mathrm{C}$, its conductivity gradually increased, after which the conductivity again diminished; in cooling it followed the same law, but in a different ratio. The modification prepared by heating to ICO C. only is Dr. Werner Siemens' Ist, or electrolyte modification, whilst the other, prepared by heating to $210^{\circ} \mathrm{C}$., is his $2 \mathrm{nd}$, or metallic modification. In the ist, the conductivity increases with rise of temperature; in the 2nd it decreases; the and is a much better conductor, but is less stable, and its conductivity increases with the intensity of the light, as shown from the following table, in which is given the effects of different intensities of light on selenium (Modification II.) obtained by Dr. Obach in Mr. Siemens' laboratory at Woolwich on the r 4 th February, 1876:-

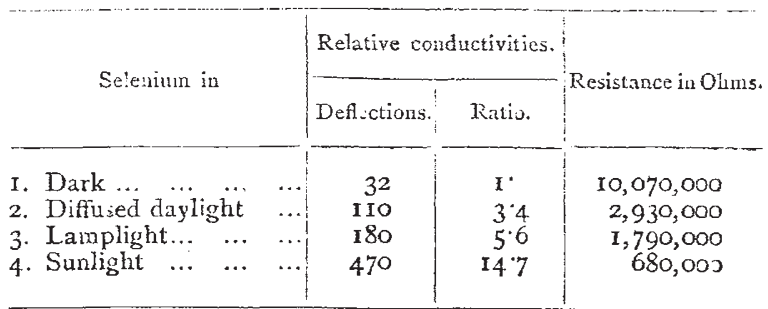

From these experimental results an extension of Helmholtz's theory is derived, viz, that the conductivity of metals varies inversely as their total heat (Helmholtz having only the sensible heat in view), and the infuence of light upon selenium is explained by a change in its molecular condition near the surface, from the first or electrolyte into the seçond or metallic modification, or, in other words, by a liberation of specific heat upon the illuminated surface of the crystalline selenium.

In testing the sensitive selenium plate in the different parts of the spectrum, it was shown that the actinic ray exercised no sensible effect, that the effect increases as we gradually approach the dark red, and that beyond that point the effect again decreases, reaching almost zero in the heat rays; the value of the material then for purposes of photometry is apparent. 